\title{
Population pharmacokinetics and bioavailability of tacrolimus in kidney transplant patients
}

\author{
75013 Paris, France \\ What is already known about this subject \\ - In spite of its success in ensuring graft survival, \\ therapeutic use of tacrolimus is complicated by its narrow \\ therapeutic index and wide intra- and interpatient \\ variability. \\ - Some studies of population pharmacokinetics have \\ already been conducted in liver transplant recipients and \\ in paediatric patients.
}

Marie Antignac, ${ }^{1}$ Benoit Barrou, ${ }^{4}$ Robert Farinotti,' Philippe Lechat ${ }^{3}$ \& Saïk Urien ${ }^{2}$

${ }^{1}$ Pharmacy Department, Pitié Salpêtrière Hospital, ${ }^{2}$ Pharmacology Department, Centre René Huguenin, Saint-Cloud, ${ }^{3}$ Pharmacology

Department, Pitié Salpêtrière Hospital and ${ }^{4}$ Department of Urology Surgery, Pitié Salpêtrière Hospital, AP HP-47 Bd de l'hôpital,

What this study adds

- Our work determined population pharmacokinetic parameters, in particular bioavailability, in kidney transplant recipients and the relative importance of factors influencing the disposition of tacrolimus.

- Clearance was modelled and days postoperation and corticosteroids dose were significant covariates.

\section{Correspondence}

Marie Antignac, Pharmacy

Department, Pitié Salpêtrière

Hospital, AP HP-47 Bd de l'hôpital,

75013 Paris, France.

Tel.: + 33142162001

Fax: + 33142162285

E-mail:

marie.antignac@psl.ap-hop-paris.fr

\section{Keywords}

kidney, population pharmacokinetics,

tacrolimus, transplantation

\section{Received}

9 October 2006

Accepted

23 January 2007

Published OnlineEarly

10 April 2007

\begin{abstract}
Aims
The use of tacrolimus is complicated by its narrow therapeutic index and wide intraand interpatient variability. Tacrolimus population pharmacokinetics, including bioavailability, were investigated in an adult kidney transplant cohort to identify patient characteristics that influence pharmacokinetics.

\section{Methods}

The database (drug monitoring data) included 83 adult kidney transplant recipients and analysis was performed by a population approach with NONMEM. Data were collected during the first months after transplantation. Patients were administered oral or intravenous tacrolimus as part of a triple immunosuppressive regimen that also included mycophenolate mofetil and corticosteroids. Subsequent doses were adjusted on the basis of clinical evidence of efficacy and toxicity as in routine therapeutic drug monitoring.
\end{abstract}

\section{Results}

A one compartment open model with linear absorption and elimination adequately described the data. The typical value of minimal clearance was $1.8 \pm 0.2 \mathrm{I} \mathrm{h}^{-1}$. Clearance increased with time post transplantation to reach $50 \%$ of maximal value after $3.8 \pm 0.5$ days, with a maximal value of $5.6 \mathrm{I} \mathrm{h}^{-1}$. Moreover clearance increased by approximately 1.6 fold (range $0.5-1.6$ ) if the dose of prednisone was $>25 \mathrm{mg}$. The typical value for volume of distribution, $V,\left(98 \pm 13 / \mathrm{kg}^{-1}\right)$ was similar to reported values in kidney transplant patients. The oral bioavailability of tacrolimus was poor and ranged from 11.2 to $19.1 \%$. No covariates significantly influenced $V$ or $F$.

\section{Conclusions}

The number of days postoperation and corticosteroid dose were significant covariates influencing tacrolimus clearance. 


\section{Introduction}

Tacrolimus is a potent immunosuppressive agent used as primary or rescue immunosuppressive therapy in transplant patients [1].

In spite of its success in ensuring graft survival, therapeutic use of tacrolimus is complicated by its narrow therapeutic index (between 5 and $15 \mathrm{ng} \mathrm{ml}^{-1}[2,3]$ ), wide intra- and interpatient variability and the risk of drug interactions with concurrently used medications [2].

It has been shown that trough tacrolimus blood concentrations are significantly related to clinical endpoints, i.e. there was a significant correlation between increased trough concentration and decreased risk of acute rejection [4]. Also it has been shown that monitoring trough tacrolimus whole blood concentrations below $15 \mathrm{ng} \mathrm{ml}^{-1}$ decreased the occurrence of nephrotoxicity [5].

These factors make defining an optimal dosing schedule for this drug difficult [6]. There is a poor correlation between tacrolimus dose and trough concentrations, supporting the need for additional information on the factors that influence the pharmacokinetic characteristics of the drug [7].

The aims of this study were a) to investigate the population pharmacokinetics of tacrolimus in an adult kidney transplant cohort using routine drug monitoring data and b) to identify the patient characteristics that influenced pharmacokinetic parameters to help physicians in transplant patient care.

\section{Methods}

Patients and data collection

A retrospective analysis of data from 83 adult kidney transplant recipients at a single centre was performed. Patients were receiving tacrolimus as primary immunosuppressant therapy and were undergoing routine therapeutic drug monitoring. Patients underwent transplant surgery between January 2003 and September 2004. Data were collected during the first 2 months following transplantation after initiation of tacrolimus treatment.

For each patient, the following covariates were recorded: 1) body weight (BW), age, size, gender (SEX) and dialysis duration before transplantation (months) (DIA), 2) surgery parameters: graft origin (brain death or living donor) and cold ischaemic time (RMIN), 3 ) days postoperation (POD, the value 1 corresponded to the transplantation date), 4) concomitant immunosuppressive drug dose: prednisone (mg) (PRD), methylprednisolone (mg) (MPRD) and cumulative corticosteroid dose (mg) (CORT), mycophenolate mofetil (mg) (MMF) and 5) biological and clinical data: aspar- tate aminotransferase (IU l ${ }^{-1}$ ) (ASAT), alanine aminotransferase (IU l ${ }^{-1}$ ) (ALAT), proteinaemia $\left(\mathrm{g} \mathrm{l}^{-1}\right)$ (PROT), serum creatinine concentration $\left(\mu \mathrm{mol} \mathrm{l}^{-1}\right)$ $\left(\mathrm{S}_{\mathrm{CR}}\right)$.

\section{Drug administration}

Patients were administrated oral or intravenous tacrolimus as part of a triple immunosuppressive regimen that also included mycophenolate mofetil and corticosteroids. The recommended initial dose of tacrolimus was generally low, approximately $0.015 \mathrm{mg} \mathrm{kg}^{-1}$ twice daily. Subsequent doses were adjusted on the basis of clinical evidence of efficacy and toxicity and to maintain tacrolimus trough blood concentrations between 5 and $10 \mathrm{ng} \mathrm{ml}^{-1}$ in the first 3 months following transplantation. Oral doses of tacrolimus were usually administered, but some patients received the drug intravenously at the beginning of treatment, and were changed to an oral formulation after a few days.

\section{Therapeutic drug monitoring}

In the immediate post transplantation period, blood samples were collected twice or thrice weekly (before the morning dose) until concentrations were stabilized. Thereafter, blood samples were collected once a week or more frequently if justified (suspicion of rejection or adverse event).

\section{Analytical methods}

Concentrations of tacrolimus in whole blood were assessed using microparticle enzyme immunoassay (MEIA) performed on the IMx platform [6, 8]. According to the manufacturer's information, the lower limit of quantification of the assay is $1.5 \mathrm{ng} \mathrm{ml}^{-1}$ and it is linear over the range $1.5-30 \mathrm{ng} \mathrm{ml}^{-1}$. Blood samples exceeding the upper limit of the calibration range $\left(30 \mathrm{ng} \mathrm{ml}^{-1}\right)$ were diluted according to the manufacturer's protocol. Although the antitacrolimus monoclonal antibody recognizes not only the parent drug but also three of its metabolites (M-II, M-III and MV), the cross reactivity for other metabolites was less than the minimum detectable sensitivity. The interassay variability (coefficient of variation, $\mathrm{CV} \%$ ) with tacrolimus concentrations of 5,11 and $22 \mathrm{ng} \mathrm{ml}^{-1}$ was $1.7 \%, 1.8 \%$ and $2.8 \%$, respectively. The intra-assay variability (CV\%) with 5,11 and $22 \mathrm{ng} \mathrm{ml}^{-1}$ was $8.7 \%, 5 \%$ and $4.1 \%$, respectively (manufacturer's information).

\section{Population pharmacokinetic modelling}

Pharmacokinetic analysis was carried out using the nonlinear mixed effects modelling program NONMEM (version V, level 1.1, double precision) [9]. The popula- 
tion analysis was undertaken using the first order conditional estimation (FOCE) method with the subroutines ADVAN2 TRANS2. Tacrolimus blood concentrations after intravenous and oral administration were simultaneously analyzed according to a one-compartment pharmacokinetic model [10] with linear absorption and elimination. This simultaneous analysis of both intravenous and oral data allowed bioavailability, $F$, to be estimated. Parameters of the structural model were tacrolimus clearance (CL), volume of distribution $(V)$, bioavailability $(F)$ and absorption rate constant $\left(k_{\mathrm{a}}\right)$.

Deviation of the 'true' value of a given pharmacokinetic parameter $\left(\mathrm{CL}_{\mathrm{j}}, V_{\mathrm{j}}\right)$ for the $\mathrm{jth}$ individual from the 'typical value' in the population (TV $(\mathrm{CL}), \mathrm{TV}(V)$, $\mathrm{TV}(F)$ ) is unique to population modelling and can be expressed as follows:

$$
\begin{aligned}
\mathrm{CL}_{\mathrm{j}} & =\mathrm{TV}\left(\mathrm{CL}_{1}\right)+\eta_{\mathrm{jCL}} \\
V_{\mathrm{j}} & =\mathrm{TV}\left(V_{1}\right)+\eta_{\mathrm{jV}} \\
F_{\mathrm{j}} & =\mathrm{TV}\left(F_{1}\right)+\eta_{\mathrm{jF}}
\end{aligned}
$$

In this additive model, $\eta_{\mathrm{jcl}}, \eta_{\mathrm{jv}}$ and $\eta_{\mathrm{jF}}$ are random variables distributed with zero means and respective variances of $\omega^{2}{ }_{C L}, \omega^{2}{ }_{V}$ and $\omega_{F}^{2}$ which can be estimated by NONMEM and which represent the intersubject pharmacokinetic variability in the population. NONMEM also estimates residual (error) variability between the observed response (i.e. whole blood drug concentration) and that predicted by the model. These differences $\left(\varepsilon_{\mathrm{ij}}\right)$ are due to intrasubject pharmacokinetic variability and can arise from different factors, including variation in drug assays, time of blood collections, time of dosing, model misspecification. Thus,

$$
C_{\mathrm{ij}}=C_{\text {pred ij }}+\varepsilon_{\mathrm{ij}}
$$

where $C_{\mathrm{ij}}$ is the ith observed concentration for the jth individual, $C_{\text {pred ij }}$ is the whole blood tacrolimus concentration predicted by the pharmacokinetic model, and $\varepsilon_{\mathrm{ij}}$ (difference between $C_{\mathrm{ij}}$ and $C_{\text {pred ij }}$ ) is a randomly distributed term of zero mean, and variance, $\sigma^{2}$. Other error models, proportional or exponential were also investigated, for example:

$$
\begin{aligned}
& \mathrm{CL}_{\mathrm{j}}=\mathrm{TV}(\mathrm{CL}) \times\left(1+\eta_{\mathrm{jCl}}\right) \\
& \mathrm{CL}_{\mathrm{j}}=\mathrm{TV}(\mathrm{CL}) \times \mathrm{e}^{\eta \mathrm{jCL}}
\end{aligned}
$$

The effect of a covariate was assessed by the chi-squared test of the difference between the objective function values (OFV) of the structural model (without covariate) and the model including the covariate. Models were tested and a decrease in OFV was referred to the chi-squared distribution to assess significance, i.e. a decrease in OFV of 10.8 was significant at $\alpha=0.001$.
During each step in the model building process, improvements to the model were assessed by evaluation of the agreement between the observed and predicted whole blood concentrations, and increases in the precision of the parameter estimates, as well as reduction of the terms for intersubject variability and random residual variability. Assessment of the log likelihood ratio test was also conducted as a means of assessing improvement in the model. An intermediate multivariate model was then obtained including all selected covariates. In order to keep only those covariates with the largest contribution to predict tacrolimus pharmacokinetics in a final multivariate model, a change of 10.8 units $(P<0.001$, one degree of freedom $)$ in the OFV was required for the retention of a parameter during backward stepwise multiple regression analysis. At this step, typical values of pharmacokinetic parameters and reduction in the interindividual variability estimate were also considered.

The accuracy and robustness of the final population model were assessed using a bootstrap method [11]. A bootstrap involves repeated random sampling, with replacement, of the original data set to produce another data set of the same size as the original but with a different combination of subjects (and their data). As the number of bootstrap samples approaches infinity, the standard deviations of the parameters approach the 'true' (but unknown) standard deviation. This resampling was repeated 1000 times and the values of the parameters estimated from the bootstrap procedure were compared with the estimates obtained from the original data set. An appreciable discrepancy between the parameter estimates from the original data and the estimated bootstrap mean values reduces confidence in the model. The entire procedure was performed in an automated fashion using Wings for NONMEM (http://wfn sourceforge.net/). This procedure also provided nonparametric statistics (median, 2.5th, 97.5th percentiles) of the population parameters.

\section{Results}

Patients and data collection

Data were collected retrospectively from 83 kidney transplant recipients during the 2 months after initiation of tacrolimus treatment. Fourteen kidney grafts were taken from living donors and 69 from cadaveric donors. Patient characteristics are presented in Table 1.

The mean time to initiation of tacrolimus treatment was 5.2 days. The doses of drug given are shown in Table 2. The 25 patients who received intravenous therapy after transplantation were switched to oral drug 
Table 1

Characteristics of the 83 patients (54 M/29 F)

\begin{tabular}{|c|c|c|c|c|}
\hline & Mean & SD & Median & Range \\
\hline \multicolumn{5}{|l|}{ Characteristics } \\
\hline Age (years) & 45 & 13 & 46 & $16-67$ \\
\hline Bodyweight before transplantation $(\mathrm{kg})$ & 68 & 14 & 69 & $30-105$ \\
\hline Bodyweight $(\mathrm{kg})$ & 66 & 13 & 69 & $29-100$ \\
\hline Dialysis duration before transplantation (months) & 37 & 40 & 24 & $0-264$ \\
\hline \multicolumn{5}{|l|}{ Surgery parameters } \\
\hline Ischaemic duration (min) & 1018 & 562 & 975 & $5-2220$ \\
\hline \multicolumn{5}{|l|}{ Medical care } \\
\hline Hospitalization duration (days) & 19 & 9 & 15 & $10-68$ \\
\hline Days postoperation (days) & 38 & 27 & 33 & $1-158$ \\
\hline \multicolumn{5}{|l|}{ Biological and clinical data } \\
\hline Aspartate aminotransferase $\left(\mathrm{IU}^{-1}\right)$ & 27 & 23 & 22 & $7-298$ \\
\hline Alanine aminotransferase $\left(\mathrm{IU} \mathrm{I}^{-1}\right)$ & 57 & 77 & 34 & $5-997$ \\
\hline Proteinaemia $\left(\mathrm{g}^{-1}\right)$ & 64 & 6.6 & 64 & $44-88$ \\
\hline Haemoglobin $\left(\mathrm{gl}^{-1}\right)$ & 10.3 & 1.5 & 10.1 & $7.0-15.6$ \\
\hline Serum creatinine concentration $\left(\mu \mathrm{mol} \mathrm{I}^{-1}\right)$ & 150 & 75 & 136 & $42-840$ \\
\hline \multicolumn{5}{|l|}{ Associated treatments } \\
\hline Prednisone (mg) & 22 & 4 & 20 & $0-30$ \\
\hline Methylprednisolone (mg) (17 patients) & 116 & 230 & 30 & $30-1000$ \\
\hline Mycophenolate mofetil (mg) & 914 & 338 & 1000 & 0-2000 \\
\hline
\end{tabular}

Table 2

Characteristics of tacrolimus treatment

\begin{tabular}{|c|c|c|c|c|}
\hline Tacrolimus treatment & Mean & SD & Median & Range \\
\hline Dose $(\mu g)$ & 2792 & 1233 & 3000 & $500-7000$ \\
\hline Dose $\left(\mu g \mathrm{~kg}^{-1}\right)$ & 44 & 22 & 42 & $5-138$ \\
\hline Number of samples & 1589 & & & \\
\hline Initial dose ( $n=83$ patients) ( $\left.\mathrm{mg} \mathrm{kg}^{-1}\right)$ & 0.02 & 0.09 & 0.02 & $0.01-0.04$ \\
\hline Initial i.v. dose ( $n=25$ patients) $\left(\mathrm{mg} \mathrm{kg}^{-1}\right)$ & 0.013 & 0.005 & 0.013 & $0.006-0.024$ \\
\hline Initial oral dose ( $n=58$ patients) $\left(\mathrm{mg} \mathrm{kg}^{-1}\right)$ & 0.02 & 0.09 & 0.02 & $0.01-0.04$ \\
\hline Tacrolimus concentration ( $\mathrm{ng} \mathrm{m}^{-1}$ ) & 6.3 & 2.6 & 6.1 & $0.3-21.4$ \\
\hline
\end{tabular}

24 or $48 \mathrm{~h}$ after the beginning of treatment. The other 53 patients received only oral tacrolimus.

\section{Population pharmacokinetics}

A total of 1589 trough whole blood concentrations were available for population modelling (Figure 1). The mean number of sampling points per subject was $19.1 \pm 4.7$ (range 1-33). A one-compartment model adequately described the data. Because only trough tacrolimus concentrations were available, the absorption rate constant $\left(k_{\mathrm{a}}\right)$ could not be estimated and was fixed to $4.5 \mathrm{~h}^{-1}$, the value from a previous study by Jusko et al. [10].

Inter-subject and residual variabilities were best described by exponential and proportional plus additive error models, respectively. Inter-subject variabilities (ISV, $\eta$ ) were then estimated for CL, $V$ and $F$.

No covariates significantly influenced $V$ or $F$. In a (forward) modelling building step, the inclusion of POD, corticosteroid dosage particularly prednisone (PRD) and methylprednisolone (MPRD), age, alanine aminotransferase $\left(\mathrm{IU} \mathrm{l}^{-1}\right)$ and proteinaemia $\left(\mathrm{g} \mathrm{l}^{-1}\right)$ on CL produced a significant decrease in OFV. In the (backward) elimination step, only POD and prednisone dosage were retained. CL was positively related to POD via a sigmoid function (Figure 2). High prednisone dosage ( $>25 \mathrm{mg}$ ) also influenced CL, and was retained in the final model because its deletion caused an increase of 28 units in OFV. Table 3 summarizes the effects of the covariates on CL. 


\begin{tabular}{|c|c|c|c|}
\hline Covariate & Objective function value (OFV) & OFV decrease & Summary of covariate effects on \\
\hline & 3430 & 0 & reported) \\
\hline Days postoperation & 3398 & -32 & \\
\hline Prednisone dose + days postoperation & 3370 & -60 & \\
\hline
\end{tabular}

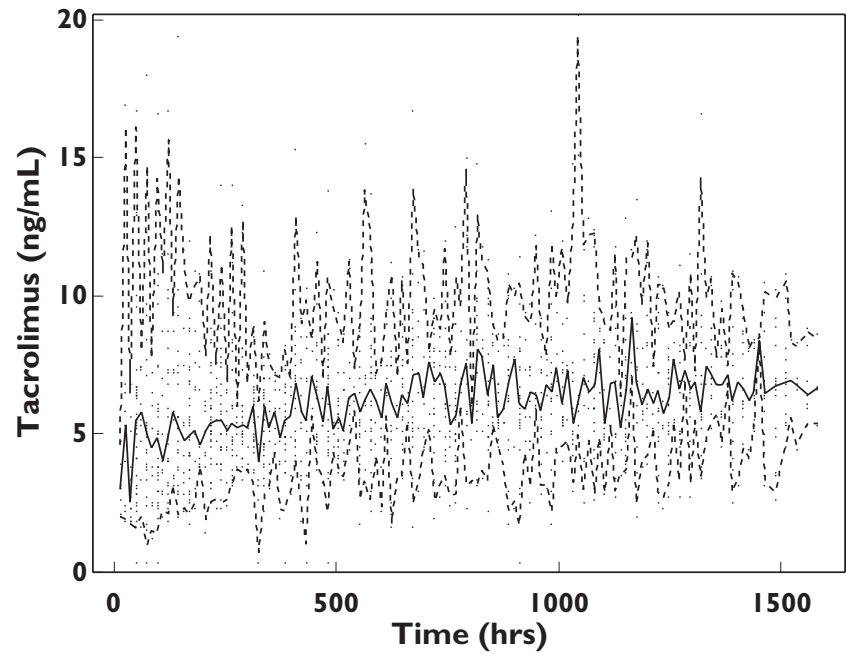

Figure 1

Tacrolimus observed trough whole blood concentrations vs. time (.). Median, solid line; 2.5th and 97.5th percentiles, dashed lines

The final relationship describing CL was:

$$
\mathrm{CL}=\mathrm{CL}_{\text {min }} \times\left[1+\frac{\mathrm{POD}^{\gamma \mathrm{CL}}}{\mathrm{POD}^{\gamma \mathrm{CL}}+\mathrm{TCL}_{50}^{\gamma \mathrm{CL}}}\right] \times \mathrm{EPRD}
$$

where $\mathrm{CL}_{\min }$ is the minimal $\mathrm{CL}$ value when $\mathrm{POD}=0$, $\mathrm{TCL}_{50}$ is the time needed to obtain $50 \%$ of $\mathrm{CL}_{\max }, \gamma_{\mathrm{CL}}$ is the sigmoidicity coefficient, $\mathrm{EPRD}=1+\theta \mathrm{PRD}$ if prednisone dosage $>25 \mathrm{mg}$ or 1 if not.

At this step, other $k_{\mathrm{a}}$ values were tried (1.5, 2 and 3) and new runs were performed. Modification of the $k_{\mathrm{a}}$ value did not result in significant changes in OFV or other parameters.

Figure 3 depicts the goodness-of-fit plots obtained for the final model. The final model was then subjected to a bootstrap analysis. As shown in Table 4, the mean parameter estimates obtained from the bootstrap process, 910 successful runs out of 1000 scheduled, were not statistically different from the estimates previously obtained with the original dataset.

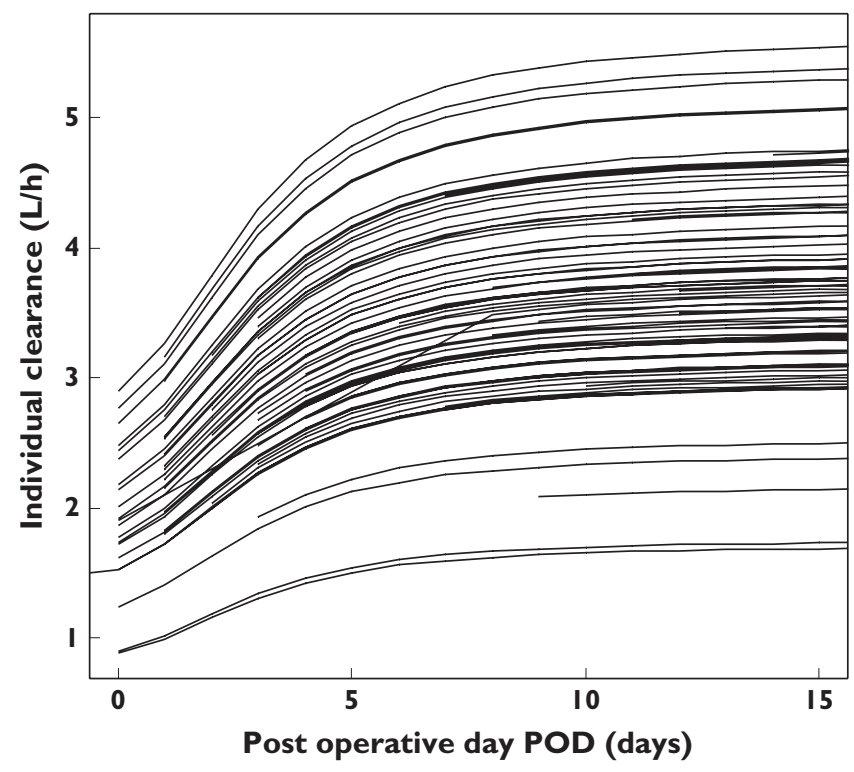

Figure 2

Individual clearance values as a function of days postoperation. Lines are drawn according to the final population model

\section{Discussion}

In this study, we estimated the population pharmacokinetic parameters of tacrolimus in adult kidney transplant recipients and identified the factors affecting its pharmacokinetics. A one-compartment open model with firstorder absorption and elimination was optimal for modelling the data, as previously reported in a population analysis performed in adults [12].

In the present study, the typical value of minimal clearance was $1.81 \pm 0.221 \mathrm{~h}^{-1}$, with a maximal value of $5.55 \mathrm{l} \mathrm{h}^{-1}$, including maximal POD and PRD effects (for oral clearance, assuming a mean bioavailability $F$ of $13.7 \%$, the corresponding minimal and maximal CL/F values were 13.2 and $40.51 \mathrm{~h}^{-1}$ ). Previous studies of pharmacokinetics [13, 14] and a population study [12] have reported similar values for tacrolimus in kidney transplant recipients.

Clearance increased with days post-transplantation to reach $50 \%$ of maximal value after $3.81 \pm 0.53$ days 
a

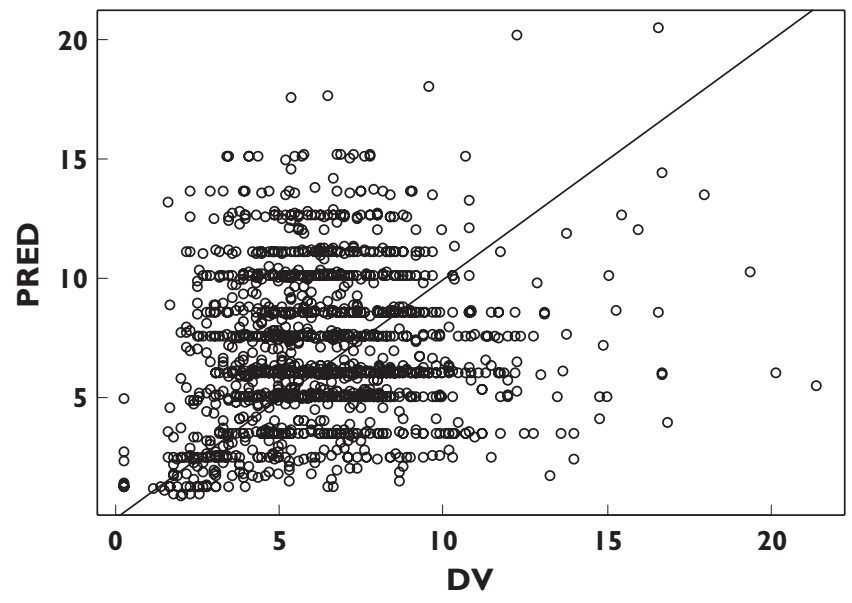

b

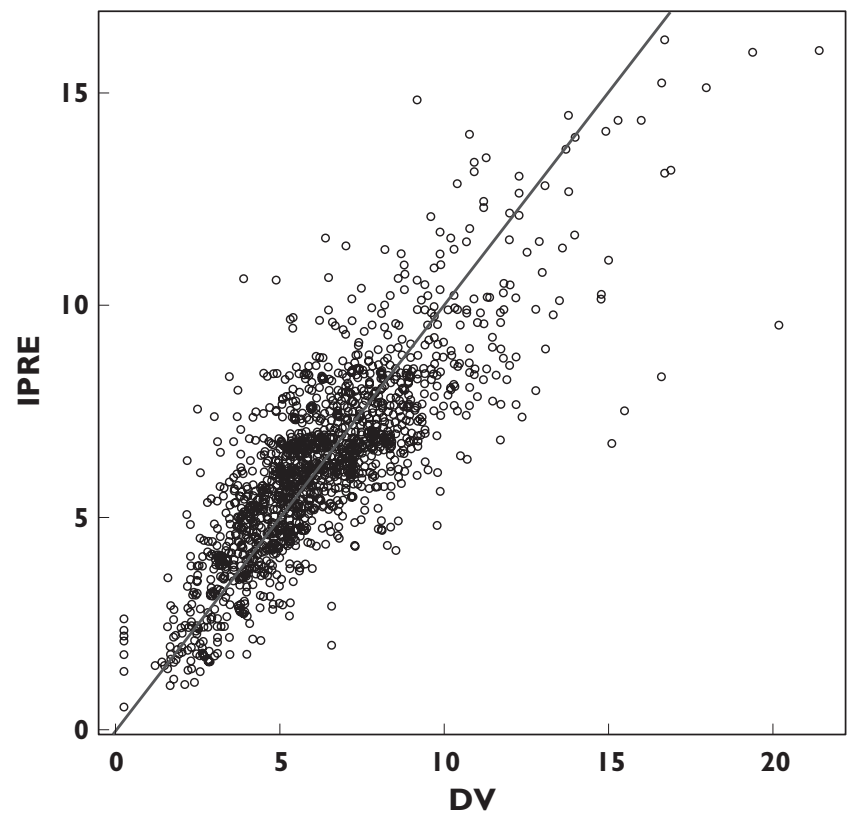

Figure 3

a) Model-predicted (PRED) vs. observed (DV) trough whole blood tacrolimus concentrations $\left(\mathrm{ng} \mathrm{ml}^{-1}\right)$. The solid line is the line of identity. The mean bias $( \pm \mathrm{SD})$ was $-0.64( \pm 3.7) \mathrm{ng} \mathrm{ml}^{-1}$, not significantly different from 0. b) Individual model-predicted (iPRED) vs. observed (DV) trough whole blood tacrolimus concentrations $\left(\mathrm{ng} \mathrm{ml}^{-1}\right)$. The solid line is the line of identity. The mean bias $( \pm$ SD) was $-0.02( \pm 1.52)$ $\mathrm{ng} \mathrm{ml} l^{-1}$, not significantly different from 0

(TCL 50\%). Moreover clearance increased by approximately $1.6(0.5-1.6)$ if the prednisone dose was $>25 \mathrm{mg}$.

POD was identified as a major covariate that described the recovery of tacrolimus CL. This covariate has been already identified in liver transplant recipients [15] and living-donor-liver adult [16, 17] and paediatric transplant recipients [18]. Aweeka et al. [19] reported that the clearance of tacrolimus was higher in post than prekidney transplants recipients. Several studies in adults have reported an increase in the dose of tacrolimus required to maintain similar trough concentrations with increasing time post transplantation [20-22]. In the present study, clearance increased until a plateau was reached post transplantation ( 2 months). Some factors, such as changes in gastrointestinal motility after surgery, could explain the low clearance immediately after surgery and recovery after a few days. After a long duration of surgery, as in transplantation, some disorders have been observed and the time to obtain the maximal value for clearance could correspond to the recovery of metabolic function. This could be due to alterations in drug metabolism related to hepatorenal syndrome.

After surgery, patients received intravenous methylprednisolone and 2 or 3 days later were transferred to oral prednisone at an initial dose of $30 \mathrm{mg}$ which could be decreased by steps of $2.5 \mathrm{mg}$ according to clinical parameters. Our model showed that when prednisone dosage was $>25 \mathrm{mg}$, CL was increased. This could have resulted from corticosteroid induction of CYP3A [23]. After organ transplantation, little information is available on the pharmacokinetic interactions between tacrolimus and low dose steroids. In a study of 83 renal transplant recipients, it was shown that the higher the steroid dose, the higher the dose of tacrolimus needed to achieve target trough concentrations [24]. Similarly, Undre et al. [20] reported a significant correlation between apparent clearance and mean oral corticosteroid dosage $(r=0.94)$ during months $2-12$ post transplantion in 303 kidney transplant recipients, indicating that corticosteroids increased the metabolism of tacrolimus. These results are in agreement with our model.

The typical value of $V\left(98 \pm 131 \mathrm{~kg}^{-1}\right)$ in our study was similar to reported values in other kidney transplant recipients [13]. No covariate influenced $V$ as in other population pharmacokinetic studies in kidney [12] or liver $[16,17]$ transplant recipients.

This was the first estimation of tacrolimus bioavailability in adult kidney recipients in a population pharmacokinetic study. The oral bioavailability of tacrolimus was poor and ranged from 11.2 to $19.1 \%$ in previous studies $[13,14,25]$ in adult kidney recipients, similar to our estimate of $13.7 \pm 1.6 \%$. The bootstrap analysis confirmed the wide variability of this parameter, with an asymetrical confidence interval between 6 and 23\%. The low bioavailability of tacrolimus could be due to gut metabolism or to poor oral absorption of the drug. Incomplete absorption of tacrolimus is largely responsible for the low bioavailability of the drug in rats [26]. 


\begin{tabular}{|c|c|c|c|c|}
\hline \multirow[b]{2}{*}{ Parameter } & \multicolumn{2}{|c|}{ Original dataset } & \multicolumn{2}{|c|}{ Bootstrap* } \\
\hline & Mean & SE & Median & percentiles \\
\hline \multicolumn{5}{|l|}{ Structural model } \\
\hline \multicolumn{5}{|l|}{ Clearance } \\
\hline $\operatorname{TV}\left(C L_{\min }\right)\left(\mathrm{I} \mathrm{h}^{-1}\right)$ & 1.81 & 0.22 & 1.78 & $1.10-12.3$ \\
\hline $\mathrm{TCL}_{50}$ & 3.81 & 0.53 & 3.77 & $1.59-14.3$ \\
\hline$\gamma_{\mathrm{Cl}}$ & 2.54 & 0.94 & 2.42 & $0.40-13.50$ \\
\hline$\theta_{\mathrm{PRD}}$ & 0.575 & 0.036 & 0.618 & $0.510-273$ \\
\hline \multicolumn{5}{|l|}{ Volume of distribution } \\
\hline$V(\mathrm{I})$ & 98.4 & 13.1 & 96.6 & $56.4-273$ \\
\hline \multicolumn{5}{|l|}{ Bioavailability } \\
\hline$F(\%)$ & 13.7 & 1.57 & 12.8 & $6.4-22.9$ \\
\hline \multicolumn{5}{|l|}{ Absorption constant } \\
\hline$k_{\mathrm{a}}$, fixed $\left(\mathrm{h}^{-1}\right)$ & 4.5 & - & 4.5 & - \\
\hline \multicolumn{5}{|l|}{ Statistical model } \\
\hline Residual additive variance, $\sigma\left(\mathrm{ng} \mathrm{ml}^{-1}\right)$ & 0.96 & 0.56 & 0.98 & $0.35-1.54$ \\
\hline Residual proportional variance, $\sigma(\%)$ & 18.6 & 9.9 & 18.0 & $0.07-0.25$ \\
\hline$\omega_{\text {Clmin }}(\%)$ & 31 & 17 & 31 & $13-146$ \\
\hline$\omega_{V}(\%)$ & 79 & 38 & 79 & $55-176$ \\
\hline$\omega_{F}(\%)$ & 32 & 18 & 34 & $13-143$ \\
\hline
\end{tabular}

\section{Table 4}

Population pharmacokinetic parameters of tacrolimus in 83 adult patients and bootstrap validation

*Mean of 910 bootstrap analyses; $S E$, standard error of the estimate; $T V\left(C L_{\text {min }}\right)$, $T C L_{50}, \gamma_{C l}, V$ and $F$ typical values of $C L_{\text {min }} ; T C L_{50}, \gamma_{C L}, V$ and $F$, respectively; $\theta_{P R D}$ influential factor for PRD on CL; $\omega$, intersubject variance; $\sigma$, intrasubject variance.

Tacrolimus, however, is poorly bioavailable in patients awaiting renal transplantation (mean bioavailability of $14 \%$, range 6-36\%) [14]. This observation explains why tacrolimus is administered intravenously during the immediate postoperative period.

In conclusion, clearance, volume of distribution and bioavailability of tacrolimus were estimated using retrospective drug monitoring data. From this the relative importance of factors influencing tacrolimus disposition in adult renal transplant recipients was assessed. Days postoperation and corticosteroid dose were significant covariates influencing tacrolimus clearance.

We acknowledge the assistance of Y. Touitou (Biochemistry Department).

Competing interests: None to declare.

\section{References}

1 Plosker GL, Foster RH. Tacrolimus: a further update of its pharmacology and therapeutic use in the management of organ transplantation. Drugs 2000; 59: 323-89.

2 Venkataramanan R, Swaminathan A, Prasad T, Jain A, Zuckerman S, Warty V, McMichael J, Lever J, Burckart G,
Starzl T. Clinical pharmacokinetics of tacrolimus. Clin Pharmacokinet 1995; 29: 404-30.

3 Kershner RP, Fitzsimmons WE. Relationship of FK506 whole blood concentrations and efficacy and toxicity after liver and kidney transplantation. Transplantation 1996; 62: 920-6.

4 Staatz C, Taylor P, Tett S. Low tacrolimus concentrations and increased risk of early acute rejection in adult renal transplantation. Nephrol Dial Transplant 2001; 16: 1905-9.

5 Backman L, Nicar M, Levy M, Distant D, Eisenstein C, Renard T, Goldstein R, Husberg B, Gonwa TA, Klintmalm G. FK506 trough levels in whole blood and plasma in liver transplant recipients. Correlation with clinical events and side effects. Transplantation 1994; 57: 519-25.

6 Holt DW, Armstrong VW, Griesmacher A, Morris RG, Napoli KL, Shaw LM. International Federation of Clinical Chemistry/ International Association of Therapeutic Drug Monitoring and Clinical Toxicology Working Group on immunosuppressive drug monitoring. Ther Drug Monit 2002; 24: 59-67.

7 Jusko WJ, Piekoszewski W, Klintmalm GB, Shaefer MS, Hebert MF, Piergies AA, Lee CC, Schechter P, Mekki QA. Pharmacokinetics of tacrolimus in liver transplant patients. Clin Pharmacol Ther 1995; 57: 281-90.

8 Grenier FC, Luczkiw J, Bergmann M, Lunetta S, Morrison M, Blonski D, Shoemaker K, Kobayashi M. A whole blood FK 506 assay for the IMx analyzer. Transplant Proc 1991; 23: 2748-9. 
9 Beal SL. Conditional estimation methods. In NONMEM users guide. University of California, San Francisco, CA, 1992.

10 Jusko WJ. Analysis of tacrolimus (FK 506) in relation to therapeutic drug monitoring. Ther Drug Monit 1995; 17: 596-601.

11 Parke J, Holford NH, Charles BG. A procedure for generating bootstrap samples for the validation of nonlinear mixed-effects population models. Comput Meth Programs Biomed 1999; 59: 19-29.

12 Staatz CE, Willis C, Taylor PJ, Tett SE. Population pharmacokinetics of tacrolimus in adult kidney transplant recipients. Clin Pharmacol Ther 2002; 72: 660-9.

13 Tuteja S, Alloway RR, Johnson JA, Gaber AO. The effect of gut metabolism on tacrolimus bioavailability in renal transplant recipients. Transplantation 2001; 71: 1303-7.

14 Gruber SA, Hewitt JM, Sorenson AL, Barber DL, Bowers L, Rynders G, Arrazola L, Matas AJ, Rosenberg ME, Canafax DM. Pharmacokinetics of FK506 after intravenous and oral administration in patients awaiting renal transplantation. J Clin Pharmacol 1994; 34: 859-64.

15 Antignac M, Hulot JS, Boleslawski E, Hannoun L, Touitou Y, Farinotti $R$, Lechat $P$, Urien $S$. Population pharmacokinetics of tacrolimus in full liver transplant patients: modelling of the post-operative clearance. Eur J Clin Pharmacol 2005; 61: 409-16.

16 Staatz CE, Willis C, Taylor PJ, Lynch SV, Tett SE. Toward better outcomes with tacrolimus therapy: Population pharmacokinetics and individualized dosage prediction in adult liver transplantation. Liver Transpl 2003; 9: 130-7.

17 Fukatsu S, Yano I, Igarashi T, Hashida T, Takayanagi K, Saito H, Uemoto S, Kiuchi T, Tanaka K, Inui K. Population pharmacokinetics of tacrolimus in adult recipients receiving living-donor liver transplantation. Eur J Clin Pharmacol 2001; 57: 479-84.

18 Yasuhara M, Hashida T, Toraguchi M, Hashimoto $Y$, Kimura M, Inui K, Hori R, Inomata Y, Tanaka K, Yamaoka Y.
Pharmacokinetics and pharmacodynamics of FK 506 in pediatric patients receiving living-related donor liver transplantations. Transplant Proc 1995; 27: 1108-10.

19 Aweeka FTBL, Gambertoglio JG, Vicente F. Comparative pharmacokinetics of orally (PO) and intravenously (IV) administered tacrolimus (FK) in pre- and post-kidney transplant recipients. Clin Pharmacol Ther 1993; 53: 151.

20 Undre NA, Schafer A. Factors affecting the pharmacokinetics of tacrolimus in the first year after renal transplantation. European Tacrolimus Multicentre Renal Study Group. Transplant Proc 1998; 30: 1261-3.

21 Pou L, Brunet M, Andres I, Rodamilans M, Lopez R, Corbella J. Influence of posttransplant time on dose and concentration of tacrolimus in liver transplant patients. Transpl Int 1998; 11: S270-1.

22 Christiaans M, van Duijnhoven E, Beysens T, Undre N, Schafer $A$, van Hooff J. Effect of breakfast on the oral bioavailability of tacrolimus and changes in pharmacokinetics at different times post transplant in renal transplant recipients. Transplant Proc 1998; 30: 1271-3.

23 Rendic S, Di Carlo FJ. Human cytochrome P450 enzymes: a status report summarizing their reactions, substrates, inducers, and inhibitors. Drug Metab Rev 1997; 29: 413-580.

24 Anglicheau D, Verstuyft $C$, Laurent-Puig P, Becquemont $L$, Schlageter $\mathrm{MH}$, Cassinat B, Beaune $\mathrm{P}$, Legendre $\mathrm{C}$, Thervet $\mathrm{E}$. Association of the multidrug resistance-1 gene single-nucleotide polymorphisms with the tacrolimus dose requirements in renal transplant recipients. J Am Soc Nephrol 2003; 14: 1889-96.

25 Saito K, Suwa M, Nakagawa Y, Utsugi R, Tanikawa T, Tomita Y, Takahashi K. Study of pharmacokinetic parameters of tacrolimus by different oral administration periods in renal transplantation. Transplant Proc 2002; 34: 1726-9.

26 Iwasaki K, Shiraga T, Nagase K, Hirano K, Nozaki K, Noda K. Pharmacokinetic study of FK 506 in the rat. Transplant Proc 1991; 23: 2757-9. 